\title{
Evolution of Posttraumatic Stress Disorder and Future Directions
}

\author{
Susan L. Ray
}

The knowledge that trauma can cause long-term physiological and psychological problems has been recognized for centuries. Today, such suffering would be classified as the characteristic symptoms of posttraumatic stress disorder (PTSD). Nurses in all practice settings are increasingly caring for individuals suffering from military trauma, natural disasters, and interpersonal violence such as childhood sexual, physical, and emotional abuse, intimate partner violence, and collective violence. This article discusses how the diagnosis of PTSD evolved over the course of history, limitations of the PTSD diagnostic category, and additional diagnostic categories for trauma. Implications for nursing practice and future directions for research are explored.

$\mathrm{T}$ RAUMA WAS A confusing concept that originally meant physical trauma or organic damage to the central nervous system. Trauma came from the ancient Greek word "trauma," which meant to "wound" or "pierce," which was used to refer to the bodily wounds or injury suffered by soldiers from the piercing of their armor (Spiers \& Harrington, 2001). In its later usage, particularly in medical and psychiatric literature, trauma was understood as a wound inflicted upon the mind, rather than upon the body (Caruth, 1996). People's responses to psychological trauma might be understood as a result of "piercing" through their protective mental defenses (Spiers \& Harrington, 2001, p. 213).

Throughout history, the suffering of human beings to situations of extreme adversity has always been regarded with great interest and curiosity. The knowledge that trauma can cause long-term physiological and psychological problems has been recognized for centuries. Homer's lliad contained powerful descriptions of soldiers' reactions to war traumatization and stresses such as withdrawal, grief, and feelings of guilt toward fallen comrades (Fagles, 1990). Homer's epic emphasized three common events of heavy, continuous combat, be- trayal of thémis ("what is right") by a commander, the living feeling dead themselves, and berserk-like rage (Shay, 1994).

In fiction and poetry, one can also find examples of how to cope with traumatization such as in Oliver Twist by Charles Dickens, the story of a boy who came to terms with the early death of his parents. Pepys (1703/2001) described the extended sensory imprint following exposure and the flashback recollection of the Great Fire of London in 1666 evoked by an insignificant trigger. He wrote, "How strange that to this very day I cannot sleep at night without great fear of being overcome by fire. Last night, I was awake until almost two o'clock in the morning, because I could not stop thinking about the fire" (p. 81).

In 1865, Charles Dickens described suffering from symptoms of anxiety, memory, and concentra-

\footnotetext{
From the The University of Western Ontario, London, Ontario, Canada.

Address reprint requests to Susan L. Ray, RN, PhD, Faculty of Health Sciences, The University of Western Ontario, HSA \#32, London, Ontario, Canada N6A 5C1.

E-mail address: slray@uwo.ca

n 2008 Elsevier Inc. All rights reserved.

0883-9417/1801-0005 $\$ 34.00 / 0$

doi: 10.1016/j.apnu.2007.08.005
} 
tion problems, irritability, hyperarousal, disturbed sleep, sudden alarm, nightmares, dissociation, and multiple somatic complaints following his involvement in a train crash (Turnbull, 1998a). Such suffering throughout history and over the course of many wars was known variously as soldiers' heart, battle fatigue, shell shock, combat neurosis, combat exhaustion, and even pseudocombat fatigue (Shay, 1994).

Today, such suffering would be classified as the characteristic symptoms of Post Traumatic Stress Disorder (PTSD). The purpose of this article will be to discuss how the diagnosis of PTSD evolved over the course of history, limitations of the PTSD diagnostic category, and the need for additional diagnostic categories for trauma. Implications for nursing practice and future directions for research into the study of trauma will be explored.

\section{THE EVOLUTION OF PTSD}

Trimble (1981) discussed case studies of railway accident survivors of the 1700 s with a history of head injury. He explored the biological components which produce PTSD symptoms and equated the term with postconcussion syndrome. According to Trimble, the English surgeon Erichsen attributed conspicuous psychological abnormalities following railway accidents to microtraumas of the spinal cord, which then led to the concept of the "railroad spine syndrome." This original connection drawn by Erichsen was later contradicted by the surgeon Page (1885) who objected to the phrase "concussion of the spine." Page argued that injuries to the spinal cord were unlikely and that fright, fear, and alarm contributed to the disorder. He introduced the concepts of "nerve shock" and "functional disorders." Although Page stated that nervous shock is psychological in origin, it resulted in physiologic malfunctioning of the nervous system. Putnam (1883) contended that many of these cases such as railroad spine syndrome could be identified as hysterical neuroses. Oppenheim first coined the term traumatic neurosis and placed the main seat of the disturbance in the cerebrum (Lamprecht \& Sack, 2002). The term trauma, which until then had been used exclusively in surgery, was thus introduced into psychiatry (Kinzie \& Goetz, 1996).

These early descriptions, based on clinical observations attempted to base a new syndrome on assumed pathology of the spinal cord or heart disease with limited phenomenological data. Inter- preting the role of trauma itself became the biggest problem in understanding posttrauma syndromes. Although the exogenous causation stood in the foreground of the railway traumas, the psychoanalytic view placed endogenous factors in the foreground, thus deemphasizing external reality (Lamprecht \& Sack, 2002).

\section{The Boer, Crimean, and American Civil War}

During the early 1800 s, military doctors diagnosed soldiers with exhaustion following the stress of battle. This exhaustion was characterized by mental shutdown due to individual or group trauma. Like today, soldiers during the 1800 s were not supposed to be afraid or show any fear in the heat of battle. The only treatment for this exhaustion was to bring the afflicted soldiers to the rear for a while, and then they would be sent back to the battle. Through extreme and often-repeated stress, the soldiers became fatigued as part of their body's natural shock reaction.

Disordered action of the heart or valvular diseases of the heart were documented in the Boer War, and subsequent reports and death certificates indicated a functional disorder (Jones \& Wessely, 2001). Myers (1870) coined the term soldiers' heart to describe a disorder that included extreme fatigue, tremors, dyspnea, palpitations, sweating, and sometimes complete syncope among soldiers in combat. Da Costa (1871), an army surgeon in the American Civil War, found "irritability of the heart," "effort syndrome," and "Da Costa syndrome" among Civil War and Crimean combat veterans. He described the frequent involvement of the heart as an almost constant symptom of traumatic neurosis, with only a few instances of serious cardiac disease (Lamprecht \& Sack, 2002). Instances of sudden paralysis or loss of sensation were identified as traumatic hysterical neurosis (Ramsay, 1990).

The late 19th century: Traumatic hysteria, neurasthenia, and neurosis

Healy (1993) explored the history of PTSD and the questions raised by Freud and Janet as to whether hysteria was precipitated by environmental events. Hysteria, melancholia, and hypochondria were the major types of neurosis described in the late 19th century. At the Salpetriere in Paris, Charcot and Janet pointed out the importance of traumatic experience for the origin of hysteria or dissociative symptoms. Although hysteria had been 
considered an affliction of women, Charcot, as well as Briquet, described several cases of working-class men, most of whose hysteria (conversion symptoms) followed work-related accidents. Charcot demonstrated that paralysis could result from hypnotic suggestion and initially deduced that there was a latent flaw in the nervous system (although he could not demonstrate it anatomically).

Janet agreed that some of the hysteria, such as that seen following railroad accidents, was a form of neurosis but also noted that the shock could be imaginary. Hysterical symptoms included paralysis, contractions, disordered gait, tremors, and shaking. Janet was the first to systematically study dissociation as a critical process in the reaction to overwhelming stress and subsequent symptoms (van der Kolk \& van der Hart, 1989). Beard (1869) coined the term neurasthenia or nervous exhaustion to cover nonspecific emotional disorders, fatigue, insomnia, headache, hypochondriasis, and melancholia. Neurasthenia was common in the early 1900 s and was recognized to occur after emotional trauma (Kinzie \& Goetz, 1996).

Freud (1896/1962) described early childhood sexual trauma in the Aetiology of Hysteria. He recognized that traumatic repetitive dreams brought the patient back to prior situations and accidents which were in conflict with his pleasure principle because unpleasurable subjects were recollected and worked over in the mind. Attempts by Freud to explain this was felt by critics to be inadequate. The rejection of his theory led him to minimize the external events and concentrate on premorbid problems, such as intrapsychic conflict (Miller, 1997).

Traumatic neurosis was used by Kraepelin (1899/2002) to describe reactions to accidents and other disasters. The early searches for an etiology, first in the organic area and then in the intrapsychic conflicts, greatly influenced subsequent research to the detriment of other approaches to knowledge development. One effect of the separation between neurology and psychiatry was the insistence that disorders were either functional (which became synonymous with psychological) or organic in nature. Thus, the concept of an interaction became lost (Trimble, 1981).

\section{World War I}

Ferenczi, Abraham, Simmel, and Jones (1921) studied World War I combat stress reactions and applied Freud's then current theories about uncon- scious conflict, rather than his original idea about trauma. Bailey, Williams, and Kamora (1929) published a definitive work on neuropsychiatry in World War I which referred throughout to Freudian psychology as a theoretical construct for their data. Da Costa's work on effort syndrome became a popular diagnosis during the war (Turnbull, 1998b). The largest number of psychiatric cases in the war involved neurosis, including neurasthenia or "shell shock," which was coined by Myers (1915), a British military psychiatrist.

Mott (1919) gave one of the best descriptions of the major forms of war neurosis, hysteria, and neurasthenia. He wrote that physical shock and horrifying conditions could cause fear, which in turn produced an intense effect on the mind. Hysterical symptoms included paralysis, contractions, disordered gait, tremors, and shaking. Neurasthenia symptoms included lassitude, fatigue, weariness, headaches, and particularly vivid and terrifying dreams. Another symptom described by Mott in detail for the first time was a startle reflex. In 1926, the U.S. Army reported that no new psychiatric syndrome was found in World War I. Even the Russian literature (Ronchevsky, 1944) listed no unique syndromes.

The Traumatic Neuroses of War by Kardiner, White, and French (1941) and War Stress and Neurotic Illness by Kardiner (1947) are seminal psychological works on the evolution of PTSD. Kardiner included the most extensive follow-up of patients from World War I. He developed the concept of "physioneurosis" which indicated bodily involvement. Kardiner differentiated the normal action syndrome from its alteration through trauma in terms of the symptomology (Lamprecht \& Sack, 2002). Symptoms included features such as fixation on the trauma, constriction of personality functioning, and atypical dream life. In most cases, the organic etiology became untenable, and the syndromes were forced into the existing nomenclature of traumatic hysteria or traumatic neurasthenia (Kinzie \& Goetz, 1996).

\section{World War II}

At the onset of War World II, the skeptics regarded shell shock or war neurosis as a heterogeneous group with many factors involved including malingering as well as psychogenic (Turnbull, 1998a). Brill (1943) commented on the many terms used to describe the affected soldiers such as 
exhaustion neurosis, shell shock, fright neurosis, and asthenia. Although the reactions were caused by fear, shock, and physical strain, they were also found in nonservice men and in men never exposed to shelling in warfare.

As the events of World War II unfolded, psychoanalytic concepts underwent modifications, and multiple analytic concepts were used to interpret war-related neurosis. These theoretical concepts represented an attempt to explain the multiple symptoms seen in war neurosis in terms of an intrapsychic model, which downplayed the role of the trauma itself.

As the war continued, more American, British, and Canadian studies began to describe and name syndromes found among armed services personnel such as acute exhaustion, war fatigue, war neurosis, and old soldier's syndrome. The sheer volume of observations by well-known psychiatrists gave clinical validity to these findings (Lamprecht \& Sack, 2002).

Cannon (1932) defined the fighting and escaping principles in both the psychological and physiological sense as a person's reaction to impending danger and the principal of homeostasis. Saul (1945) identified traumatic war experiences with the term combat fatigue and incorporated Cannon's fight-flight reaction.

In 1942, the Coconut Grove fire provided the first modern clinical descriptions of reaction to noncombatant trauma. Lindemann (1944) found psychological grief among survivors characterized by overactivity, expansiveness, some psychosomatic symptoms, irritability, avoidance of social relationships, and hostility.

Grinker and Spiegel (1945), two American psychiatrists in the Army Air Force, wrote about what happens to soldiers who break under the stress of modern warfare. Sixty-five case histories were included as illustrative material with a description of various therapies used to treat the psychological casualties of combat. The most interesting aspects were the etiology of the psychoneuroses or war neuroses stated first in psychological terms and then in terms of neurophysiology. Some of the symptoms included passive dependent states, guilt and depression, aggressive and hostile reactions, and psychotic-like states.

To summarize, during the 19th century and into the mid-20th century, there was an ongoing debate as to whether the etiology of traumatic disorders was psychological or organic. The recognition that there was an interaction between the psychological and neurophysiologic was not clearly identified until post-War World II.

\section{Post-World War II}

Krystal (1969) edited the groundbreaking work Massive Psychic Trauma, which looked at "concentration camp syndrome" of Nazi Germany's concentration camp survivors after World War II. Psychological Aspects of Stress edited by Harry S. Abram (1970) is cited frequently in the trauma literature as a major contribution in the evolution of PTSD. Abram examined the human response to stressful events including psychological reactions to life-threatening illness, concentration camps, emergency situations, combat, and the stresses of outer space. As follow-up information on concentration camp victims became increasingly available; a chronic syndrome was described by many authors with a high degree of agreement on symptoms with both physical and psychological factors.

Selye and Fortier (1950) introduced the "General Adaptation Syndrome" with the three phases of alarm, resistance, and exhaustion. As a result, the term stress entered everyday language. Selye (1974) introduced the concept of heterostasis, thereby indicating the existence of an area between maintaining a normal equilibrium and succumbing to physical and mental breakdown. Once again the external environment was discovered as the instigator of threat and danger. Burgess and Holstrom (1974) described "Rape Trauma Syndrome" noting that the flashbacks and nightmares resembled the traumatic neuroses of war.

The first concession to a unique syndrome was published by the American Psychiatric Association (APA; 1952) in the first edition of its Diagnostic and Statistical Manual of Mental Disorders (DSM1) which coincided with the Korean War. The DSM-I called what is now known as PTSD "Stress Response Syndrome" caused by gross stress reaction under the category of transient situational personality disorder.

The inclusion of Stress Response Syndrome recognized that some reactions could occur in normal persons at times of extreme physical and emotional stress. However, it was specified that the reactions were reversible and that the ego should return to normal under treatment. This Freudian view became even harder to maintain with the 
follow-up studies from World War II and the increasing data from concentration camp victims (Bradford \& Bradford, 1947). However, this information did not influence DSM-II (APA, 1968) in which the only comparable diagnosis given was situational adjustment reaction of adult life.

\section{The Vietnam War and PTSD}

The Vietnam War and the work by Horowitz (1976) influenced the authors of the DSM-III (APA, 1980) to recognize a century of clinical observation and to include PTSD in the official nomenclature. The suffering of many veterans confirmed by longterm follow-up documented the severe impairments of chronic cases. Horowitz made a major contribution when he successfully argued that an expectable predictable sequence of symptoms follow abnormally stressful life events. Horowitz organized posttraumatic symptoms into intrusive effects and denial or avoidance effects which had been originally described by Freud. The former are attempts to revive the trauma or to live through repetition of it. The negative reactions are attempts to avoid memories or actions associated with the forgotten trauma. This became the organizing topology of DSM-III. The DSM-III focused on overt symptoms to avoid dilemmas brought on by theoretical attempts at etiology. The inclusion of the diagnostic criteria of PTSD in DSM-III and the World Health Organization (1992) International Classification of Diseases and Related Health Problems, 10th Revision (ICD-10) was a step forward and helped many of those suffering from trauma.

The revised DSM-III (DSM-III-R; APA, 1987) separated PTSD from the ordinary stressors (i.e., divorce, failure, rejection, and financial problems) that are characterized in DSM-III as adjustment disorders. The stressor criterion for PTSD had to be outside the range of usual human experience (i.e., war, torture, rape, or natural disasters). The stressor criterion had to cause marked distress to almost everyone and induce intense fear, terror, and helplessness.

In the DSM-IV (APA, 1994), the stressor criterion contained both objective and subjective features. Criterion $A 1$ required that an individual must have experienced, witnessed, or been confronted with an event or events that involved actual or threatened death or serious injury or a threat to the physical integrity of self or others. A1 may also be expressed as disorganized and agitated behavior in children.
Criterion $A 2$ required that the person responded to the event with intense fear, helplessness, or horror.

In the current DSM-IV-TR (APA, 2000), PTSD remained in the anxiety disorder category. Presently, the necessary conditions for any definition of trauma involves a threat to either one's life or physical integrity or that of another; the threat is often accompanied by real assaults, damage, or death (Krystal, 1969; van der Kolk, 1987). The hallmark symptoms for the diagnosis of PTSD are intrusiveness or reexperiencing the trauma, hyperarousal, and avoidance such as dissociation (Table 1 DSM-IV-TR criteria).

The literature on Vietnam veterans and PTSD is vast; studies of veterans have been essential in developing and extending the concept of PTSD (Knox \& Price, 1996; Kulka et al., 1990; Shay, 1994; Wagner, Wolfe, Rotnitsky, Proctor, \& Erickson, 2000). It is fair to say that much, if not most, of what is known today about normal responses to catastrophic events, to fear, and to the threat of being killed have been learned from combat veterans. For the most part, the current criteria for PTSD in the DSM-IV-TR (APA, 2000) fit combat and peacekeeping-related trauma. However, the current diagnostic criteria only cover a small section of the overall spectrum of frequently occurring psychic and psychosomatic symptoms after traumatization (Friedhelm \& Sack, 2002).

\section{LIMITATIONS OF THE PTSD DIAGNOSTIC CATEGORY}

Many symptoms such as weakness, fatigue, and loss of will power mentioned early on and by many subsequent authors (Lamprecht \& Sack, 2002) that have historically been related to trauma did not find a place in the DSM-III-R (APA, 1987), the DSM-IV (APA, 1994), or the DSM-IV-TR (APA, 2000). Headache was a common symptom reported in both combat and concentration camp victims, as well as multiple psychophysiological reactions, particularly gastrointestinal disturbances (Friedhelm \& Sack, 2002) are not mentioned.

There are few descriptions of dissociative symptoms, except amnesia operating in PTSD. This fact is recognized by the limited dissociative symptoms required for the diagnosis of PTSD in DSM-IV-TR (APA, 2000). DSM-IV-TR (APA, 2000) reflects the ongoing ambivalence of psychiatry to maintain dissociative disorders such as dissociative identity disorder in a separate diagnostic group while still 
Table 1. DSM-IV-TR (APA, 2000)

A. The person has been exposed to a traumatic event in which both of the following were present:

1. The person experienced, witnessed, or was confronted with an event or events that involved actual or threatened death or serious injury or a threat to the physical integrity of self or others.

2. The person's response involved intense fear, helplessness, or horror.

B. The traumatic event is persistently reexperienced in one or more of the following ways:

1. Recurrent and intrusive distressing recollections of the event, including images, thoughts, or perceptions

2. Recurrent distressing dreams of the event

3. Acting or feeling as if the traumatic event were recurring (includes a sense of reliving the experience, illusions, hallucinations, and dissociative flashback episodes, including those that occur on awakening or when intoxicated)

4. Intense psychological distress at exposure to internal or external cues that symbolize or resemble an aspect of the traumatic event

5. Physiological reactivity on exposure to internal or external cues that symbolize or resemble an aspect of the traumatic event

C. Persistent avoidance of stimuli associated with the trauma and numbing of general responsiveness (not present before the trauma), as indicated by three or more of the following:

1. Efforts to avoid thoughts, feelings, or conversations associated with the trauma

2. Efforts to avoid activities, places, or people that arouse recollections of the trauma

3. Inability to recall an important aspect of the trauma

4. Markedly diminished interest or participation in significant activities

5. Feeling of detachment or estrangement from others

6. Restricted range of that affect (e.g., unable to have loving feelings)

7. Sense of a foreshortened future (e.g., does not expect to have a career, marriage, children, or normal lifespan)

D. Persistent symptoms of increased arousal, not present before the trauma, as indicated by two or more of the following:

1. Difficulty falling or staying asleep

2. Irritability or outbursts of anger

3. Difficulty concentrating

4. Hypervigilance

5. Exaggerated startle response

E. Duration of the disturbance (symptoms in criteria B, C, and D) is more than 1 month

F. The disturbance causes clinically significant distress or impairment in social, occupational, or other important areas of functioning.

Acute: If duration of symptoms is less than 3 months.

Chronic: If duration of symptoms is 3 months or more. With delayed onset: If onset of symptoms is at least 6 months after the stressor.

NoTE. Diagnostic criteria for PTSD.

acknowledging a close relationship between psychological trauma and dissociative symptoms (van der Kolk, Herron, \& Hostetler, 1994).

\section{ADDITIONAL DIAGNOSTIC \\ CATEGORIES FOR TRAUMA}

The DSM-IV field trial studied 440 treatmentseeking patients and 128 community residents and found that victims of prolonged interpersonal trauma, particularly early in life, had a high incidence of problems with (a) regulation of affect and impulses, (b) memory and attention, (c) selfperception, (d) interpersonal relations, (e) somatization, and (f) systems of meaning (Roth, Newman, Pelcovitz, van der Kolk, \& Mandel, 1997). Complex PTSD (C-PTSD) or disorders of extreme stress not otherwise specified (DESNOS) attempted to recognize the long-term psychological responses of individuals exposed to prolonged periods of violence such as various forms of captivity, childhood physical or sexual abuse, domestic violence, and organized sexual exploitation (Roth et al., 1997; van der Kolk, Roth, Pelcovitz, Sunday, \& Spinazzola, 2005). However, these profound psychological alterations that occurred among individuals exposed to prolonged periods of captivity or total control by another such as hostages, prisoners of war, concentration camp survivors, and survivors of long-term interpersonal violence (Matussek, 1975; Niederland, 1964) were not captured in PTSD as outlined by the DSM-IV-TR (APA, 2000). The DSM -IV-TR (APA, 2000) listed C-PTSD or DESNOS not as a distinct diagnosis but under the rubric of "associated and descriptive features" of PTSD (p. 425).

\section{DISCUSSION}

Many authors (Bracken, 2002; Gorman, 2001; Lykes, 2000; Summerfield, 2004; Thomas \& Bracken, 2004) have questioned the inadequacy of the PTSD diagnosis to explain trauma from prolonged interpersonal violence and collective violence such as terrorism, mass murders, mass torture, genocide, and ethnic cleansing that occurs on a wide scale around the world. PTSD as a universal concept has been applied to everyone regardless of cultural, ethnic, religious background, age, gender, or context. However, its universality has been challenged because victims of violence around the world are not homogeneous and do not necessarily fit into the individualistic PTSD category (Ehrenreich, 2003; Ozer \& Weiss, 2004). Although some evidence of individual traumatization is widespread, and many individuals may 
acknowledge symptoms of PTSD, symptom presentations rarely match (or are limited to) PTSD (Baron, Jensen, \& deJong, 2004; Kagee, 2004). More commonly, traumatized individuals of longterm interpersonal violence seek help for regulation of affect and impulsivity, somatic symptoms, relationship conflicts, and dissociative symptoms (Herman, 1997; Linehan, 1993). Local observers perceived the primary consequences of collective violence in non-Western societies and cultures to be increased levels of interpersonal conflict, widespread apathy, increased drug and alcohol use, marital breakdown, and violence directed at women and children (Baron et al., 2004; Kagee, 2004).

The development of additional diagnostic categories such as C-PTSD or DESNOS, although still a work in progress, attempted to capture the multidimensional nature of breakdown in the face of trauma from prolonged interpersonal violence (van der Kolk et al., 2005). Additional diagnostic categories are needed to explain the multidimensional responses to interpersonal and collective violence.

\section{IMPLICATIONS FOR NURSING PRACTICE}

Nurses in a variety of practice settings such as psychiatry, pediatrics, maternal child, oncology, hospice, and addictions are increasingly caring for individuals suffering from military trauma, natural disasters, interpersonal violence such as childhood sexual, physical, emotional abuse, intimate partner violence, and collective violence. The nursing profession has a significant role to play in working with individuals from diverse cultural, ethnic, and religious backgrounds who are suffering from different types of trauma. Nurses need to recognize unique responses to trauma due to these differences including age and gender. Nurses must be knowledgeable about what is considered to be within a normal range and what is considered more serious pathological symptoms.

Nurses must also understand the different levels of intervention to help those suffering from trauma. First-order interventions or "psychological first aid" involve community prevention programs such as connection to social supports, fundamental needs such as food, rest, and safety, and resources for professional help (Slaikeu, 1990). It is important not to "pathologize" initial reactions and to focus on the individual's functionality (Shalev \& Ursano, 2003). When symptoms occur for a longer period of time without resolution; individuals may require crisis intervention in order to return to their premorbid level of functioning and to foster the development of additional coping skills (Dripchak \& Marvasti, 2007).

When adolescents and adults present with symptoms of pathology that are present for at least 3 months, more intensive therapeutic interventions are required such as cognitive-behavioral therapy, eye movement desensitization and reprocessing, and dialectical behavioral therapy. Play therapy is used to reenact the traumatic experience for children from ages 3 to 11 years in order to arrive at a better resolution of the conflict (Dripchak \& Marvasti, 2004). Specialized training in trauma for advanced practice nurses in mental health is required for these intensive therapeutic interventions.

\section{FUTURE DIRECTIONS FOR RESEARCH}

Future research into trauma needs to extend beyond the traditional preoccupation on PTSD as the sole outcome of traumatization and more closely attend to the full range of disordered psychological domains including disturbances in perceptions, information processing, affect regulation, and personality development that are now relegated to various other comorbidies. Further studies are needed in regard to C-PTSD or DESNOS as additional diagnoses into understanding the complexity of prolonged interpersonal violence. PTSD is limited when called upon to comprehend the responses of individual victims of collective violence at the hands of others. To view these responses as simply a more severe form of the response of victims to more encapsulated traumatic experiences such as a natural disaster or as involving merely additional associated symptoms fails to capture the overall impact of these events (Ehrenreich, 2003). To focus on the symptoms of individuals rather than the impact of traumatic events on the collective experience of their communities and cultures minimizes the experience of the victims. Thus, there is a pressing need for research into understanding trauma from collective violence in communities and cultures from around the world.

\section{CONCLUSION}

The diagnostic category of PTSD has evolved over the past two centuries. At present, there is a need to understand trauma beyond the singular 
entity and limitations of PTSD. Further knowledge and additional diagnostic categories in regard to various sources of trauma such as prolonged interpersonal violence and collective violence are needed. Differences in responses to various forms of trauma from diverse cultural, ethnic, and religious backgrounds around the globe need to be studied. Nurses in a variety of settings are in unique positions both in practice and research to further our understanding of those suffering from various forms of trauma from around the world.

\section{REFERENCES}

Abram, H. S. (1970). Psychological aspects of stress. Springfield, IL: Thomas.

American Psychiatric Association. (1952). Diagnostic and statistical manual of mental disorders (1st ed.) Washington, DC: Author.

American Psychiatric Association. (1968). Diagnostic and statistical manual of mental disorders (2nd ed.) Washington, DC: Author.

American Psychiatric Association. (1980). Diagnostic and statistical manual of mental disorders (3rd ed.) Washington, DC: Author.

American Psychiatric Association. (1987). Diagnostic and statistical manual of mental disorders (3rd ed., revised). Washington, DC: Author.

American Psychiatric Association. (1994). Diagnostic and statistical manual of mental disorders (4th ed.) Washington, DC: Author.

American Psychiatric Association. (2000). Diagnostic and statistical manual of mental disorders (4th ed., text revision). Washington, D.C.: Author

Bailey, P., Williams, F. E., \& Kamora, P. O. (1929). Neuropsychiatry, Vol. 10: The Medical Department of the United States Army in the World War. Washington, DC: Office of the Surgeon General, U.S. Army.

Baron, N., Jensen, S. B., \& de Jong, J. (2004). The mental health of refugees and internally displaced peoples. In J. Fairbanks, M. Friedman, J. deJong, B. Green, S. Solomon (Eds.), Guidelines for Psychosocial Policy and Practice in Social and Humanitarian Crises: Report to the United Nations. New York: United Nations.

Beard, G. M. (1869). Neurasthenia or nervous exhaustion. Boston Medical and Surgical Journal, 80, 217-221.

Bracken, P. (2002). Trauma: Culture, meaning and philosophy London: Whurr Publishers.

Bradford, J. M. \& Bradford, E. J. (1947). Neurosis in escaped prisoners of war. British Journal of Medical Psychology, $20,422-435$.

Brill, N. Q. (1943). War neurosis. Journal of Laboratory and Clinical Medicine, 28, 489-498.

Burgess, A. W. \& Holstrom, L. (1974). Rape trauma syndrome. American Journal of Psychiatry, 147, 887-892.

Cannon, W. B. (1932). The wisdom of the body. New York: Norton Publishers.

Caruth, C. (1996). Unclaimed experience: Trauma, narrative, and history. Baltimore, MA: Hopkins University Press.
Da Costa, J. M. (1871). On irritable heart: A clinical study of a form of cardiac disorder and its consequences. American Journal of the Clinical Sciences, 61, 17-52.

Dripchak, V. L. \& Marvasti, J. A. (2004). Treatment approaches for sexually abused children and adolescents: Play therapy and cognitive behavioral therapy. In J. A. Marvasti (Ed.), Psychiatric treatment of victims and survivors of sexual trauma: A neuro-bio-psychological approach (pp. 155-176). Illinois: Charles Thomas Publishers.

Dripchak, V. L. \& Marvasti, J. A. (2007). The multi-dimensional impact of terrorism on civilians: Treatment implications for nurses. On the Edge: The Official Newsletter of the International Association of Forensic Nurses, 13(1) 5-8.

Ehrenreich, J. H. (2003). Understanding PTSD: Forgetting "Irauma". Journal of Social Issues, 3(1), 15-28.

Fagles, R. (1990). lliad/Homer. R. Fagles (Trans.). New York: Viking Penguin.

Ferenczi, S., Abraham, K., Simmel, E., \& Jones, E. (1921). Psychoanalysis and the war neuroses. London: International Psychoanalytical Press.

Freud, S. (1962). The aetiology of hysteria. (J. Strachey, Trans.) London: Hogarth Press (Original work published 1896).

Friedhelm, L. \& Sack, M. (2002). Post-traumatic stress disorder revisited. American Psychosomatic Society, 64, 222-237.

Gorman, W. (2001). Refugee survivors of torture: Trauma and treatment. Professional Psychology: Research and Practice, 32, 443-451.

Grinker, R. R. \& Spiegel, J. P. (1945). Man under stress. New York: McGraw-Hill Book Company.

Healy, D. (1993). Images of trauma: From hysteria to posttraumatic stress disorder. London: Faber and Faber.

Herman, J. L. (1997). Trauma and recovery: The aftermath of violence from domestic abuse to political terror. New York: Basic Books.

Horowitz, M. J. (1976). Stress response syndrome. New York: Jason-Aronson.

Jones, E. \& Wessely, S. (2001). The origins of British military psychiatry before the First World War. War and Society, 19, 91-108.

Kagee, A. (2004). Do South African former detainees experience post traumatic stress? Circumventing the demand characteristics of a psychological assessment. Transcultural Psychiatry, 41, 323-346.

Kardiner, A. (1947). War ftress and neurotic illness. Washington: Research Council.

Kardiner, A., White, B. V., \& French, T. M. (1941). The traumatic neuroses of war. Washington: National Research Council.

Kinzie, J. D. \& Goetz, R. R. (1996). A century of controversy surrounding posttraumatic stress-spectrum syndromes: The impact on DSM-III and DSM-IV. Journal of Traumatic Stress, 9(2), 159-179.

Knox, J. \& Price, D. H. (1996). Healing America's warriors: Vet centers and the social contract. Retrieved December 22, 2002, from http://www.victnamcenter/events/ 1996Symposium/96papers/healing/htm.

Kraepelin, E. (2002). Lifetime editions of Kraepelin in English. London: Thoemmes Press (Original work published 1899). 
Krystal, H. (1969). Massive psychic trauma. New York: International Universities Press.

Kulka, R. A., Schlenger, W. E., Fairbank, J. A., Hough, R. L., Jordan, B. K., Marmar, C. R., et al. (1990). Trauma and the Vietnam War generation. New York: Brunner/Mazel.

Lamprecht, F. \& Sack, M. (2002). Posttraumatic stress disorder revisited. Psychosomatic Medicine, 64(2), 222-237.

Lindemann, E. (1944). Sympomatology and management of acute grief. American Journal of Psychiatry, 101(9), 141-148.

Linehan, M. M. (1993). Cognitive-behavioral treatment of borderline personality disorder. New York: Guilford Press.

Lykes, M. B. (2000). Possible contributions of a psychology of liberation: Whither health and human rights? Journal of Health Psychology, 5(3), 383-397.

Matussek, P. (1975). Internment and concentration camps and their consequences. New York: Springer.

Miller, L. (1997). Freud and consciousness: The first one hundred years of neuropsychodynamics in theory and clinical practice. Seminars in Neurology, 17(2), 171-177.

Mott, F. W. (1919). War neuroses and shell shock. London: Oxford University Press.

Myers, A. B. R. (1870). On the etiology and prevalence of diseases of the heart among soldiers. London: J. Churchill.

Myers, C. S. (1915). A contribution to the study of shell shock. Lancet, $188,316-320$.

Niederland, W. G. (1964). Psychiatric disorders among persecution victims: A contribution to the understanding of concentration camp pathology and its after effects. Journal of Nervous and Mental Disorders, 139, 458-474.

Ozer, E. J. \& Weiss, D. S. (2004). Who develops posttraumatic stress disorder? Current Directions in Psychological Science, 13(4), 169-172.

Page, H. (1885). Injuries of the spine and spinal cord without apparent mechanical lesion. In T.R. Trimble (Ed.), Posttraumatic neurosis: From railroad spine to whiplash (pp. 29-37). London: J. Churchill.

Pepys, S. (1703/2001). The diary of Samuel Pepys. Toronto: Random House.

Putnam, J. J. (1883). Recent investigations into the pathology of so-called concussion of the spine. Boston Medical Surgical Journal, 109, 217-220.

Ramsay, R. (1990). Invited review: Post-traumatic stress disorder; a new clinical entity? Journal of Psychosomatic Research, 34(4), 355-365.

Ronchevsky, S. P. (1944). Traumatic psychoneurosis: Problem of psycho reactive states in time of war. Sovietskii Vrachebnyi Zhurnal, 44, 359-366.

Roth, S., Newman, E., Pelcovitz, D., van der Kolk, B. A., \& Mandel, F. S. (1997). Complex PTSD in victims exposed to sexual and physical abuse results from the DSM-IV field trial for posttraumatic stress disorder. Journal of Traumatic Stress, 10, 539-555.
Saul, L. J. (1945). Psychological factors in combat fatigue with special reference to hostility and the nightmares. Psychosomatic Medicine, 7, 257-272.

Selye, H. (1974). Stress without distress. New York: Lippincott.

Selye, H. \& Fortier, C. (1950). Adaptive reaction to stress. Psychosomatic Medicine, 12, 149-157.

Shalev, A. Y. \& Ursano, R. J. (2003). Mapping the multidimensional picture of acute responses to traumatic stress: From diagnosis to treatment planning. In $\mathrm{R}$. Orner \& U. Schnyder (Eds.), Reconstructing early interventions after trauma. Oxford, England: Oxford University Press.

Shay, J. (1994). Achilles in Vietnam: Combat trauma and the undoing of character. New York: Maxwell McMillan International.

Slaikeu K.A. (Ed.). (1990), Crisis intervention: A handbook for practice and research. Boston: Allyn \& Bacon.

Spiers, T. \& Harrington, G. (2001). A brief history of trauma. In T. Spiers (Ed.), Trauma: The practitioner's guide to counseling (pp. 213-21). New York: Taylor \& Francis Group.

Summerfield, D. (2004). Cross-cultural perspectives on the medicalisation of human suffering. In G. Rosen (Ed.), Posttraumatic stress disorder: Issues and controversies (pp. 1-15). New York: John Wiley.

Thomas, P. \& Bracken, P. (2004). Critical psychiatry in practice. Advances in Psychiatric Treatment, 10, 361-370.

Trimble, M. R. (1981). Post-traumatic neurosis: From railway spine to the whiplash. New York: Wiley.

Turnbull, G. J. (1998). A review of post-traumatic stress disorder Part I: Historical development and classification. Injury, 29(2), 87-91.

Turnbull, G. J. (1998). A review of post-traumatic stress disorder. Part II: Treatment. Injury, 29(3), 168-175.

van der Kolk, B. A. (1987). Psychological trauma. Washington, DC: American Psychiatric Press.

van der Kolk, B. A., Herron, N., \& Hostetler, A. (1994). The history of trauma in psychiatry. Psychiatric Clinics of North America, 17(3), 583-600.

van der Kolk, B. A., Roth, S., Pelcovitz, D., Sunday, S., \& Spinazzola, J. (2005). Disorders of extreme stress: The empirical foundation of a complex adaptation to trauma. Journal of Traumatic Stress, 18(5), 389-399.

van der Kolk, B. A. \& van der Hart, O. (1989). Pierre Janet and the breakdown in psychological trauma. American Journal of Psychiatry, 146, 1530-1540.

Wagner, A. W., Wolfe, J., Rotnitsky, A., Proctor, S. P., \& Erickson, D. J. (2000). An investigation of the impact of posttraumatic stress disorder on physical health. Journal of Traumatic Stress, 13(1), 41-55.

World Health Organization. (1992). The ICD-10 Classification of mental and behavioral disorders. World Health Organization Publication: Geneva. 